Martin Treml, Karlheinz Barck, (éds.), Erich Auerbach. Geschichte und Aktualität eines europäischen Philologen

Berlin, Kulturverlag Kadmos, 2007, 512 p.

Michael Löwy

(2) OpenEdition

Journals

Édition électronique

URL : http://journals.openedition.org/assr/12093

DOI : $10.4000 /$ assr. 12093

ISSN : $1777-5825$

Éditeur

Éditions de l'EHESS

Édition imprimée

Date de publication : 1 décembre 2007

Pagination : 157-310

ISBN : 978-2-7132-2145-3

ISSN : 0335-5985

Référence électronique

Michael Löwy, « Martin Treml, Karlheinz Barck, (éds.), Erich Auerbach. Geschichte und Aktualität eines europäischen Philologen », Archives de sciences sociales des religions [En ligne], 140 | octobre - décembre 2007, document 140-81, mis en ligne le 02 juillet 2008, consulté le 21 septembre 2020. URL : http:// journals.openedition.org/assr/12093; DOI : https://doi.org/10.4000/assr.12093

Ce document a été généré automatiquement le 21 septembre 2020.

(c) Archives de sciences sociales des religions 


\section{Martin Treml, Karlheinz Barck, (éds.), Erich Auerbach. Geschichte und Aktualität eines europäischen Philologen}

Berlin, Kulturverlag Kadmos, 2007, 512 p.

Michael Löwy

1 Ce recueil d'essais est dédié à une des grandes figures de la culture judéo-allemande, l'historien de la littérature Erich Auerbach (1892-1957). Professeur à l'Université de Marburg, exclu par le nazisme comme juif en 1935, il va s'exiler d'abord à Istanbul et, onze années plus tard, aux États-Unis où il deviendra professeur de philologie romane à l'université de Yale. Son ouvrage le plus connu, Mimésis, est une histoire des origines du réalisme dans la littérature occidentale, de l'Antiquité aux temps modernes.

2 La première partie de ce recueil vise à cerner la place d'Erich Auerbach au centre d'un vaste réseau de correspondances et dialogues, avec des figures comme Walter Benjamin (essai de Robert Kahn), Siegfried Kracauer (Johannes Otto Riedner) ou Leo Spitzer (Manfred Nauman). Suivent des essais sur ses principaux concepts, le réalisme, l'historicisme, ainsi qu'une section sur sa postérité, notamment aux États-Unis où Edward Saïd a longuement dialogué avec son œuvre (Jane O Newman et Herbert Landenberger).

3 Juif agnostique, E. Auerbach s'intéressait beaucoup aux rapports entre littérature et religion. Un des essais les plus originaux de ce recueil est celui que Richard Faber dédie à sa «sociologie littéraire de la religion» (Literaturreligionssoziologie) : partant de la définition de la Bible par Augustin comme sermo humilis, Auerbach détecte dans le mélange judéo-chrétien entre l'humble et le sublime le point de départ du réalisme en littérature, depuis Rabelais jusqu'aux grands auteurs russes modernes comme Tolstoï ou Dostoïevski.

4 Ce recueil contient aussi un certain nombre d'inédits de Auerbach, dont un, particulièrement intéressant, est dédié à la Divine Comédie de Dante; ce document est 
présenté à la fois dans une version écrite et, grâce à un disque $\mathrm{CD}$ inséré dans le livre, sous forme d'enregistrement oral. L'origine de ce document (retracée par Martin Vialon) est curieuse : il s'agit d'une conférence donnée par Auerbach à l'Institute for Advanced Study de Princeton en août 1949, peu après son arrivée aux États-Unis. La bande sonore avait été égarée à Princeton, mais fut découverte récemment par l'auteur de cette notice dans les archives d'un autre juif allemand exilé à Istanbul, Traugott Fuchs, qui l'avait reçue de son ami Auerbach.

Dans cette conférence, E. Auerbach revient sur le thème du réalisme, en insistant sur la présence, dans le chef d'œuvre de Dante, de cette association entre l'humble et le sublime qui caractérise, selon Augustin, l'esprit des Évangiles. La Divine Comédie est aussi, observe-t-il, l'expression la plus puissante et la plus passionnée de l'idée médiévale de l'unité chrétienne européenne - une idée déjà obsolète au XIve siècle, quand l'ouvrage avait été écrit. Cependant, pour Dante qui soutenait le parti des Gibelins, le représentant le plus éminent de cette unité n'était pas le pape - comme le prétendait le parti rival, celui des Guelfes - mais l'Empereur du Saint Empire romain germanique, successeur légitime des anciens empereurs romains. Ce choix éminemment politique explique pourquoi, dans la Divine Comédie, on trouve dans les plus profonds cercles de l'Enfer, plusieurs souverains pontifes de l'histoire récente de son époque... 